\title{
Host Range and Alternate Host of a Puccinia coronata Population from Smooth Brome Grass
}

\author{
N. J. Delgado, Department of Agronomy; C. R. Grau, Department of Plant Pathology; and M. D. Casler, \\ Department of Agronomy, University of Wisconsin, Madison 53706
}

\begin{abstract}
Delgado, N. J., Grau, C. R., and Casler, M. D. 2001. Host range and alternate host of a Puccinia coronata population from smooth brome grass. Plant Dis. 85:513-516.

A rust fungus was observed on smooth brome grass (Bromus inermis Leyss.) leaves growing in the fields of the University of Wisconsin (UW) Agricultural Research Station at Arlington, WI. The population (WPc-95A) was classified as Puccinia coronata Corda. Reports of P. coronata on $B$. inermis are rare, so a study of the pathogen host range, alternate host, and morphology of urediniospores and teliospores was undertaken. Fourteen grass species representing 10 genera were inoculated with $P$. coronata WPc-95A, which was maintained with repeated inoculations on $B$. inermis cv. PL-BDR1. Seventy-two 30-day-old seedlings of B. inermis were inoculated with urediniospores of the fungus. Infection type, pustule density, and disease incidence were recorded 15 days after inoculation. The same grass cultivars were also inoculated with aeciospores collected from Rhamnus cathartica L. located on the UW campus. To test for host specificity, urediniospores produced on aeciospore-susceptible grass species were used to reinoculate plants of $B$. inermis and the host species from which the urediniospores were derived. B. inermis, B. riparius Rehm., Festuca pratensis Huds., and Lolium perenne L. were susceptible to $P$. coronata WPc-95A. The two Bromus spp. had the highest disease incidence. $R$. cathartica was found to be an alternate host of $P$. coronata WPc-95A, as it is for $P$. coronata isolates found on $F$. pratensis. However, cross-inoculations with urediniospores from $R$. cathartica-derived aeciospore infections indicated that only urediniospores of $B$. inermis origin were capable of infecting $B$. inermis. Thus, $P$. coronata WPc-95A appears to belong to a forma speciales previously undescribed in North America.
\end{abstract}

A rust fungus was intermittently observed in breeding nurseries of Bromus inermis Leyss. during the 1990s at Arlington, WI. Reports of rust on $B$. inermis include brown rust, Puccinia recondita Roberge ex Desmaz. (2,18), and crown rust, $P$. coronata Corda $(4,8,13)$. An isolate of the rust fungus on $B$. inermis, WPc-95A, was established in a controlled environment and was classified as $P$. coronata, based on teliospore morphology.

P. coronata occurs on numerous Bromus spp. throughout much of North America, including both native and introduced species $(4,6,9-12,14)$. Although $P$. coronata has numerous physiological forms (formae speciales), most descriptions of $P$. coronata on Bromus spp. do not identify the taxon beyond the species level and contain no morphological or physical description to allow any further taxonomic identification. $P$. coronata has been reported on $B$. inermis three times in North America, in a controlled-environment inoculation experiment with $P$. coronata var. hordei (11)

Corresponding author: M. D. Casler

E-mail: mdcasler@facstaff.wisc.edu

Accepted for publication 31 January 2001.

Publication no. D-2001-0228-02R

(C) 2001 The American Phytopathological Society and unknown taxonomic forms in Alaska and South Dakota $(1,4)$.

Fraser and Ledingham (8) described an isolate of $P$. coronata that produced uredinia and telia on $B$. ciliatus, B. latiglumis, and $B$. porteri, with aecia on the alternate host, rabbit berry (Lepargyraea canadensis L.). This isolate of $P$. coronata was common in northern Saskatchewan where both $B$. ciliatus and L. canadensis occur together. The relationship of aecial hosts and aecial morphology suggested that the $P$. coronata on $L$. canadensis was distinct from $P$. coronata on Rhamnus spp. (8). These authors named this new isolate $P$. coronata f. sp. bromi, largely because of its predominance on several Bromus spp. Nevertheless, $B$. inermis was immune to $P$. coronata f. sp. bromi (8) as well as to $P$. coronata f. sp. avenae $(2,8,12)$ and $P$. coronata f. sp. holci (12). B. inermis, $B$. ciliatus, $B$. latiglumis, and B. porteri are all members of the Bromus subgenus Bromopsis; therefore, there does not appear to be any relationship between Bromus taxonomy and $P$. coronata host range on Bromus spp.

$P$. coronata Corda is a complex species consisting of numerous formae speciales that form a telial state on one or more of many grass hosts. Alternate hosts include Berchemia scandens (Hill) K. Koch, Condalia obovata (Hook), Elaeagnus commutata Bernh. ex Rydb., Lepargyraea canad- ensis (L.) Greene, and several species of Rhamnus (16). In all, 290 plant species are reported as telial hosts of $P$. coronata in 72 genera distributed among 17 tribes in four subfamilies of the Poaceae (16). Genera within the subfamily Festucoideae are common hosts of $P$. coronata and, in nature, hosts outside this subfamily are rare (16). Physiological forms of $P$. coronata generally are restricted to one telial host, but may form the aecidial state on several alternate host species (7). The objective of this study was to determine the host range, alternate host, and morphology of urediniospores and teliospores of $P$. coronata WPc-95A.

\section{MATERIALS AND METHODS}

A rust collection from infected Bromus inermis leaves in fields of the University of Wisconsin (UW) Arlington Agricultural Station was classified as $P$. coronata and named WPc-95A. Measurements of 150 urediniospores and 150 teliospores were made to characterize the population in comparison with $P$. coronata $\mathrm{f}$. sp. bromi and $\mathrm{f}$. sp. avenae (8). Measurements were made on freshly collected spores. Urediniospores were measured along their greatest diameter as length and at right angles to this for width. For teliospores, the longitudinal measurement was taken from the point of attachment of the pedicel to the apex of the crown, as described by Fraser and Ledingham (8). Teliospore width was measured across the crown. Means and standard deviations were computed.

$P$. coronata WPc-95A was maintained with repeated inoculations of $B$. inermis PL-BDR1, a cultivar developed at the U.S. Regional Pasture Research Laboratory (University Park, PA) for resistance to Pyrenophora bromi (Died.) Drechs. (3). Urediniospores of Puccinia coronata were collected from $B$. inermis PL-BDR1 plants that had been infected with the original isolate of $P$. coronata WPc-95A. Urediniospores were harvested with a vacuum pump every 2 days until the fungus sporulation ceased. The inoculum was prepared by suspending 7- to 10-day-old spores (previously stored at about $4^{\circ} \mathrm{C}$ ) in deionized water containing two drops of Tween 20 surfactant per $100 \mathrm{ml}$ of water and agitated manually. The spore concentration used was approximately 2 to $4 \times 10^{5}$ urediniospores $/ \mathrm{ml}$.

Seeds of 16 grass cultivars, representing 10 genera and 14 species (Table 1), were 
planted in $225-\mathrm{cm}^{3}$ plastic pots filled with a 50:50 ( $\mathrm{vol} / \mathrm{vol})$ mixture of peat moss and silt loam soil. One week after emergence, 72 plants per cultivar or population were transplanted to $30-\mathrm{cm}^{3}$ plastic pots filled with the same soil medium. Each plant was fertilized 15 days after transplanting with $80 \mathrm{mg}$ of $\mathrm{N}, 69 \mathrm{mg}$ of $\mathrm{P}$, and $56 \mathrm{mg}$ of $\mathrm{K}$. Inoculation was performed 4 weeks after transplanting. An air sprayer was used to uniformly apply $25 \mathrm{ml}$ of inoculum suspension per flat (72 seedlings), after which flats were placed in a dew chamber for 48 $\mathrm{h}$ and returned to the greenhouse benches under fluorescent light supplementation (14-h day length) and a temperature range of 21 to $28^{\circ} \mathrm{C}$. Pustules appeared approximately 12 to 15 days after inoculation.

The total number of pustules per leaf was determined for two leaves per cultivar using a microscope. The length and width of each leaf was determined, leaf area was computed according to the method of Casler and Carpenter (5), and the data were expressed as the number of pustules per square centimeter, or pustule density. Infection type (IT) was visually determined using a scale adapted from Roelfs (15), where $0=$ no uredinia, $1=$ chlorotic flecks (no sporulation), 2 = small uredinia sur- rounded by necrosis with limited urediniospore production, 3 = medium-size uredinia with moderate sporulation, and $4=$ large uredinia and abundant sporulation. IT was recorded for the two most heavily infected leaves per cultivar or population, which were sampled and preserved on paper towels covered with transparent tape. IT classifications were largely unambiguous, with individual plants rarely showing multiple IT classes. In these rare cases, IT scores were assigned based on the most advanced IT class. The frequency of plants with IT $\geq 2$ was recorded to determine disease incidence for each cultivar.

Aeciospores were collected from Rhamnus cathartica bushes adjacent to fields of $B$. inermis. Collections were made from five adjacent bushes with a Pasteur pipette and bulked to form a single isolate. Twelve plants each of the 16 grass cultivars were inoculated with aeciospores to determine the primary host range of this $R$. cathartica metapopulation of $P$. coronata. The inoculation, post-inoculation, and data collection protocols followed were the same as described above for the urediniospore inoculations.

Urediniospores were collected with a vacuum pump from all plants that were

Table 1. Species of grasses used in the Puccinia coronata WPc-95A pathogenicity test

\begin{tabular}{lll}
\hline Species & Common name & Cultivar \\
\hline Arrenatherum elatius (L.) Nevski & Tall oat grass & Arone \\
Avena sativa L. & Oat & Gem \\
Avena sativa L. & Oat & Ogle \\
Bromus riparius Rehm. & Meadow brome grass & Fleet \\
Bromus inermis Leyss. & Smooth brome grass & PL-BDR1 \\
Dactylis glomerata L. & Orchard grass & Justus \\
Elytrigia $\times$ muctonata (Opiz ex Bercht.) Prokud. & Hybrid wheat grass & WEm-1LR \\
Elytrigia repens (L.) Nevski & Quack grass & WEr-URS \\
Festuca arundinacea Schreb. & Tall fescue & KY-31 \\
Festuca pratensis Huds. & Meadow fescue & Laura \\
Lolium multiflorum Lam. & Italian rye grass & Florida 80 \\
Lolium perenne L. & Perennial rye grass & PR4 \\
Phalaris arundinacea L. & Reed canary grass & Rival \\
Phleum pratense L. & Timothy & Climax \\
Triticum aestivum L. & Winter wheat & Menton \\
Triticum aestivum L. & Winter wheat & Glory \\
\hline
\end{tabular}

Table 2. Mean urediniospore and teliospore dimensions ( $\mu \mathrm{m})$ for three Puccinia coronata isolates

\begin{tabular}{lccccc}
\hline & \multicolumn{2}{c}{ Urediniospores } & & \multicolumn{2}{c}{ Teliospores } \\
\cline { 2 - 3 } \cline { 5 - 6 } Organisma $^{\mathbf{a}}$ & Length & Width & & Length & Width \\
\hline$P$. coronata f. sp. avenae & $24.0 \pm 0.06$ & $20.4 \pm 0.04$ & & $60.5 \pm 0.32$ & $17.0 \pm 0.09$ \\
$P$. coronata f. sp. bromi & $20.5 \pm 0.05$ & $17.7 \pm 0.04$ & & $41.6 \pm 0.18$ & $15.3 \pm 0.07$ \\
$P$. coronata WPc-95A & $23.0 \pm 0.61$ & $19.8 \pm 0.81$ & & $56.0 \pm 1.05$ & $12.8 \pm 0.55$ \\
\hline
\end{tabular}

${ }^{a} P$. coronata f. sp. avenae and $P$. coronata f. sp. bromi are from Fraser and Ledingham (8).

Table 3. Mean values for disease incidence, infection type, and pustule density for all infected cultivars challenged with urediniospores of Puccinia coronata WPc-95A from Bromis inermis

\begin{tabular}{|c|c|c|c|}
\hline Cultivar or population & Disease incidence (\%) & Infection type ${ }^{a}$ & Pustule density $\mathrm{cm}^{-2 \mathrm{~b}}$ \\
\hline B. inermis cv. PL-BDR1 & 96 & 4 & 8.3 \\
\hline B. riparius cv. Fleet & 51 & $3-4$ & 8.1 \\
\hline Festuca pratensis cv. Laura & 3 & 2 & 0.6 \\
\hline Lolium perenne cv. PR4 & 13 & 4 & 1.7 \\
\hline
\end{tabular}

\footnotetext{
a Range of values for susceptible plants (infection type $\geq 2$ ).
}

${ }^{\mathrm{b}}$ Mean of values for susceptible plants (infection type $\geq 2$ ). infected by aeciospores and separated according to grass species host. To test for primary host specificity of these urediniospore isolates (each deriving from the original $R$. cathartica metapopulation of $P$. coronata), they were reinoculated on two host species: $B$. inermis and the species from which the urediniospores were derived. The inoculation, post-inoculation, and data collection protocols followed were the same as described above for urediniospore inoculations, with one exception: cotton swabs covered with urediniospores were used instead of the sprayer-spore suspension. Earlier (unreported) experiments had shown similar effectiveness of the spray versus cotton swab inoculation techniques. The experimental design was a randomized complete block with three replicates. Experimental units consisted of 12 seedlings of one species. The experiment was repeated twice so that 72 plants per species were evaluated for their reaction to $P$. coronata from $R$. cathartica.

\section{RESULTS AND DISCUSSION}

Urediniospores of $P$. coronata WPc-95A were orange and only slightly longer than wide (Table 2). Black telia were covered by the host epidermis and produced on the host leaves in late October. Teliospores were two-celled, clavate-oblong, orangebrown, and darkest at the tip of the apical cell. Mean teliospore length was approximately 4.4 times the width. The range of teliospore size was 40 to $70 \mu \mathrm{m}$ long and 10 to $15 \mu \mathrm{m}$ wide. Urediniospore size was less variable than teliospore size. Urediniospores and teliospores of $P$. coronata WPc95A were longer than those of $P$. coronata f. sp. bromi W. P. Fraser \& Ledingham (8) (Table 2). Teliospores of $P$. coronata WPc95A were longer than those of $P$. coronata f. sp. avenae W. P. Fraser \& Ledingham (8). Thus, $P$. coronata WPc-95A appears to be morphologically different from both $P$. coronata f. sp. avenae W. P. Fraser \& Ledingham and P. coronata f. sp. bromi W. P. Fraser \& Ledingham. A dried and pressed sample of $B$. inermis including both teliospores and urediniospores has been deposited at the Arthur Herbarium, Purdue University (accession no. PUR N652).

Using urediniospores collected from $B$. inermis $\mathrm{PL}-\mathrm{BDR} 1, P$. coronata WPc-95A caused infection in only 4 of the 16 grass cultivars (Table 3 ). The other 12 grass cultivars either showed no symptoms or developed only chlorotic or necrotic flecks. Four of these showed no visible reaction, suggesting that they are not hosts of $P$. coronata WPc-95A (Table 4). The other eight cultivars, with only chlorotic or necrotic flecks, may possess host resistance to $P$. coronata WPc-95A. Of these eight cultivars, three (Lolium multiflorum and both Triticum aestivum cultivars) have likely undergone human-directed selection 
for host resistance to some strains of $P$. coronata, whereas selection for host resistance in the others may have occurred by natural selection. Phleum pratense (nonhost in Table 4) and Phalaris arundinacea (resistant host in Table 4) were both reported to be susceptible to Puccinia coronata f. sp. avenae (8), further discriminating the host range of $P$. coronata $\mathrm{f}$. sp. avenae and $P$. coronata WPc-95A.

The two Bromus spp. had higher disease incidence than Festuca pratensis and $L$. perenne (Table 3). Infection type was similar for L. perenne and the two Bromus spp., but pustule density was higher for the Bromus spp., indicating their greater susceptibility to $P$. coronata WPc-95A. These four host species belong to one subfamily (Festucoideae) and P. coronata f. sp. lolii has been reported to infect both $F$. pratensis and L. perenne (12), which are species of closely related genera (17). $P$. coronata f. sp. lolii has not been tested on $B$. inermis. However, F. pratensis and L. perenne both showed a nonhost reaction to $P$. coronata f. sp. bromi W. P. Fraser \& Ledingham (8). Therefore, it is doubtful that $P$. coronata WPc-95A can be considered an isolate of $P$. coronata f. sp. bromi W. P. Fraser \& Ledingham.

P. coronata f. sp. bromi and f. sp. avenae induced similar nonhost reactions on $B$. inermis, $F$. pratensis, and $L$. perenne, with the exception of a host-resistance reaction of $P$. coronata $\mathrm{f}$. sp. avenae on $L$. perenne in one study (Table 5). Based on reaction to these three hosts, $P$. coronata WPc-95A appears most similar to $P$. coronata $\mathrm{f}$. $\mathrm{sp}$. lolii. However, this pattern breaks down when additional potential host species are examined. Melhus et al. (12) found Avena sativa L., Dactylis glomerata L., Festuca arundinacea Schreb., F. pratensis Huds., Lolium multiflorum Lam., L. perenne L., and Phalaris arundinacea L. to be highly susceptible to Puccinia coronata f. sp. lolii, whereas Phleum pratense showed a host-resistance reaction, and A. elatius and E. repens showed no visible reaction. Of the 10 grass species that were coincident between our study and that of Melhus et al. (12), only two ( $F$. pratensis and L. perenne) showed similar host classification for Puccinia coronata f. sp. lolii (12) and P. coronata WPc-95A (Tables 3 and 4). Similarly, the reactions of D. glomerata, Elytrigia repens, L. perenne, and Phalaris arundinacea to Puccinia coronata var. hordei (11) were decidedly different than to $P$. coronata WPc-95A (Tables 3 and 4). Thus, it appears unlikely that $P$. coronata WPc-95A is an isolate of either $P$. coronata f. sp. lolii or P. coronata var. hordei.

$B$. inermis, $B$. riparius, Elytrigia $\times$ muctonata, E. repens, $F$. pratensis, and $A$. sativa cv. Ogle were susceptible to the population of $P$. coronata collected from $R$. cathartica (IT $\geq 2$ for most plants). All other species and cultivars had IT $<2$ for all plants inoculated. Thus, $R$. cathartica is likely an alternate host of $P$. coronata WPc-95A. However, the host specificity of $P$. coronata WPc-95A is not clear from these results. When urediniospores collected from the aeciospore-infected cultivars were used to inoculate $B$. inermis plants and the hosts from which these urediniospores were derived, only urediniospores of $B$. inermis origin were able to infect $B$. inermis. A hypersensitive reaction (chlorotic flecking, IT = 1) was observed for the non- $B$. inermis urediniospore populations on $B$. inermis, whereas their respective host plants developed heavily sporulating pustules (Table 6).

Table 4. Percentage of plants showing necrotic flecks, chlorotic flecks, or no visible reaction for all 12 cultivars with little or no symptoms following inoculation with Puccinia coronata WPc-95A ${ }^{\mathrm{a}}$

\begin{tabular}{|c|c|c|c|c|}
\hline \multirow[b]{2}{*}{ Species, cultivar } & \multicolumn{3}{|c|}{ Reaction type $^{b}$} & \multirow[b]{2}{*}{ Comments } \\
\hline & NF & $\mathbf{C F}$ & NR & \\
\hline Avena sativa cv. Gem & 0.0 & 0.0 & 100.0 & No visible reaction \\
\hline A. sativa cv. Ogle & 0.0 & 0.0 & 100.0 & No visible reaction \\
\hline Festuca arundinacea & 0.0 & 0.0 & 100.0 & No visible reaction \\
\hline Phleum pratense & 0.0 & 0.0 & 100.0 & No visible reaction \\
\hline Arrenatherum elatius & 0.0 & 23.6 & 76.4 & Large size, well-defined CF \\
\hline Dactylis glomerata & 12.9 & 25.7 & 61.4 & Not well-defined flecks \\
\hline Elytrigia $\times$ muctonata & 27.5 & 29.0 & 43.5 & Medium-size, well-defined CF \\
\hline E. repens & 16.1 & 54.8 & 25.0 & Small size $C F$ \\
\hline Lolium multiflorum & 0.0 & 8.3 & 91.7 & Not well-defined flecks \\
\hline Phalaris arundinacea & 100.0 & 0.0 & 0.0 & Large-size, well-defined NF \\
\hline Triticum aestivum cv. Menton & 0.0 & 100.0 & 0.0 & Medium-size, well-defined CF \\
\hline T. aestivum cv. Glory & 0.0 & 94.3 & 6.7 & Small-size CF \\
\hline
\end{tabular}

${ }^{a}$ Inoculations were made using urediniospores from Bromis inermis PL-BDR1 plants.

${ }^{\mathrm{b}} \mathrm{NF}=$ necrotic flecks, $\mathrm{CF}=$ chlorotic flecks, and $\mathrm{NR}=$ no visible reaction.

Table 5. Summary of reaction phenotypes from three experiments in which Puccinia coronata strains were tested against Bromus inermis, Festuca pratensis, and Lolium perenne ${ }^{\mathrm{a}}$

\begin{tabular}{|c|c|c|c|c|}
\hline \multirow[b]{2}{*}{ Host species, authors ${ }^{b}$} & \multicolumn{4}{|c|}{ P. coronata form or isolate } \\
\hline & f. sp.avenae & f. sp. bromi & f. sp. lolii & WPc-95A \\
\hline \multicolumn{5}{|l|}{ B. inermis } \\
\hline Other authors & 0 & 0 & NT & NT \\
\hline Delgado, Grau, and Casler & NT & NT & NT & + \\
\hline \multicolumn{5}{|l|}{ F. pratensis } \\
\hline Other authors & 0 & 0 & + & NT \\
\hline Delgado, Grau, and Casler & NT & NT & NT & + \\
\hline \multicolumn{5}{|l|}{ L. perenne } \\
\hline Other authors & $0 / 1$ & 0 & + & NT \\
\hline Delgado, Grau, and Casler & NT & NT & NT & + \\
\hline
\end{tabular}

${ }^{\mathrm{a}} \mathrm{NT}=$ not tested, $0=$ nonhost reaction, $1=$ resistant host (weak, hypersensitive reaction), and $+=$ susceptible host.

${ }^{\mathrm{b}}$ Other authors $=$ data from Fraser and Ledingham (8) or Melhus et al. (12).

Table 6. Reaction of four grass species to urediniospores collected from pustules resulting from a Rhamnus cathartica-derived aeciospore challenge of each grass species ${ }^{\mathrm{a}}$

\begin{tabular}{lccc}
\hline & & \multicolumn{2}{c}{ Number of days post-inoculation } \\
\cline { 3 - 4 } Urediniospore origin & Inoculated grass species & $\mathbf{1 0}$ & $\mathbf{1 2}$ \\
\hline Avena sativa cv. Ogle & A. sativa cv. Ogle & $3-4$ & $3-4$ \\
& Bromus inermis & 0 & 1 \\
Elytrigia repens & E. repens & 3 & $3-4$ \\
Festuca pratensis & B. inermis & 0 & 1 \\
& F. pratensis & $3-4$ & $3-4$ \\
B. inermis & B. inermis & 0 & 1 \\
& A. sativa cv. Ogle & 0 & 1 \\
\hline
\end{tabular}

${ }^{\text {a }}$ Reaction was measured as pustule type: $0=$ no visible reaction, $1=$ chlorotic flecks without uredinia, $2=$ small uredinia with limited necrosis and some urediniospore production, $3=$ medium size uredinia with moderate sporulation, and $4=$ large uredinia with abundant sporulation. 
inermis showed differential pathogenicity to those that infected $A$. sativa, $F$. pratensis, or E. repens (Table 6).

Based on the alternate host, host range, and morphology of the urediniospores and teliospores, $P$. coronata WPc-95A is different from the population described in Canada (8) and may belong to $P$. coronata $\mathrm{f}$. sp. bromi Mühlethaler described in Germany (13). P. coronata f. sp. bromi W. P. Fraser \& Ledingham reported in Canada did not cause disease on $B$. inermis, $L$. perenne, or $F$. pratensis; its alternate host is different from $R$. cathartica; and its urediniospore and teliospore sizes are different from $P$. coronata WPc-95A. Furthermore, the German $P$. coronata f. sp. bromi Mühlethaler is known to infect $B$. inermis and $R$. cathartica is its alternate host (13).

Fraser and Ledingham (8) are the only authors to describe a Bromus-specific form of $P$. coronata in North America. They admitted that their use of the term "variety bromi" was one of convenience. This variety (or forma speciales) was most commonly observed on B. ciliatus and the alternate host $L$. canadensis in northern Saskatchewan. However, even their own data suggest that this subspecific designation was misleading. Mühlethaler (13) reported $B$. inermis to be highly susceptible to a Bromus-specific form of $P$. coronata (syn. $P$. coronifera), clearly distinguishable from Fraser and Ledingham's isolate based on pathogenicity within the genus Bromus. We cannot rule out the possibility that $P$. coronata WPc-95A is a member of this German taxon; therefore, to avoid further confusion, we do not suggest a new variety taxon for $P$. coronata WPc-95A. We suggest $P$. coronata f. sp. bromi W. P. Fraser \& Ledingham, which is widespread on $B$. ciliatus in northern Saskatchewan, should be renamed to reflect its different pathogenicity from the German isolate of $P$. coronata f. sp. bromi Mühlethaler.

\section{ACKNOWLEDGMENTS}

We thank D. Long and K. Leonard of the Cereal Disease Laboratory, USDA-ARS, St. Paul, MN for their advice and assistance with rust taxonomy, experimental methods, and critical review of our research.

\section{LITERATURE CITED}

1. Anonymous. 1960. Index of Plant Diseases in the United States. U.S. Dept. Agric. Handb. No. 165. Washington, D.C.

2. Bahadur, P., Singh, S., Goel, L. B., Sharma, S. K., Sinha, V. C., Ahmad, R. U., and Singh, B. P. 1973. Impact of grass introduction on cereal rusts in India. Indian J. Agric. Sci. 43:287-290.

3. Berg, C. C., Zeiders, K. E., and Sherwood, R. T. 1989. Registration of PL-BDR1 B. inermis germplasm. Crop Sci. 29:1578.

4. Cash, E. K. 1953. A check list of Alaskan fungi. Plant Dis. Rep. Suppl. 219:23-24.

5. Casler, M. D., and Carpenter, J. A. 1989. Morphological and chemical responses to selection for in vitro dry matter digestibility in smooth bromegrass. Crop Sci. 29:924-928.

6. Cummins, G. B. 1964. Uredinales of the Big Bend National Park and adjacent areas of
Texas. Southwest. Nat. 8:181-195.

7. Dietz, S. M. 1926. The alternate hosts of crown rust, Puccinia coronata Corda. J. Agric. Res. 33:953-971.

8. Fraser, W. P., and Ledingham, G. A. 1933. Studies of the crown rust, Puccinia coronata Corda. Sci. Agric. 13:313-323.

9. Gilbertson, R. L., Cummins, G. B., and Darnall, E. D. 1979. Indexes to W. G Solheim's mycoflora saximontanensis exixiccata. Mycotaxon 10:49-92.

10. Hanlin, R. T. 1966. Host index to the basidomycetes of Georgia. Ga. Agric. Exp. Stn. Mimeo Ser. N.S. 260.

11. Jin, Y., and Steffenson, B. J. 1999. Puccinia coronata var. hordei var. nov.: morphology and pathogenicity. Mycologia 91:877-884.

12. Melhus, I. E., Dietz, S. M., and Willey, F. 1922. Alternate hosts and biologic specialization of crown rust in America. Iowa Agric Exp. Stn. Res. Bull. 72:207-236.

13. Mühlethaler, F. 1911. Infektionsversuche mit Rhamnus befallenden Kronenrosten. Iph. D dissertation. University of Bern. Verlag von Gustav Fischer, Jena, Germany.

14. Raper, K. B., and Cooke, W. B. 1954. The 1950 foray of the Mycological Society of America. Mycologia 46:670-679.

15. Roelfs, A. P. 1984. Race specificity and methods of study. Pages 131-164 in: The Cereal Rusts. Vol. I. Origins, Specificity, Structure, and Physiology. W. R. Bushnell and A. P. Roelfs, eds. Academic Press, Orlando, FL.

16. Simons, M. D. 1970. Crown rust of oats and grasses. The American Phytopathological Society, Monogr. No. 5.

17. Xu, W. W., and Sleper, D. A. 1994. Phylogeny of tall fescue and related species using RFLPs. Theor. Appl. Genet. 88:685-690.

18. Zeiders, K. E., and Sherwood, R. T. 1986. First report of rust caused by Puccinia recondita on B. inermis. Plant Dis. 70:801. 